\title{
BMJ Open Relationship between leisure time physical activity, sedentary behaviour and symptoms of depression and anxiety: evidence from a population- based sample of Canadian adolescents
}

\author{
Marc-André Bélair, ${ }^{1}$ Dafna E Kohen, ${ }^{1,2}$ Mila Kingsbury, ${ }^{1}$ lan Colman ${ }^{1}$
}

To cite: Bélair M-A, Kohen DE, Kingsbury M, et al. Relationship between leisure time physical activity, sedentary behaviour and symptoms of depression and anxiety: evidence from a populationbased sample of Canadian adolescents. BMJ Open 2018;8:e21119. doi:10.1136/ bmjopen-2017-021119

- Prepublication history for this paper is available online. To view these files please visit the journal online (http://dx.doi. org/10.1136/bmjopen-2017021119).

Received 15 December 2017 Revised 27 July 2018 Accepted 22 August 2018

Q Check for updates

(c) Author(s) (or their employer(s)) 2018. Re-use permitted under CC BY-NC. No commercial re-use. See rights and permissions. Published by BMJ.

${ }^{1}$ School of Epidemiology and Public Health, University of Ottawa, Ottawa, Ontario, Canada

${ }^{2}$ Health Analysis Division,

Statistics Canada, Ottawa,

Ontario, Canada

Correspondence to

Dr lan Colman;

icolman@uottawa.ca

\section{ABSTRACT}

Background Physical and sedentary activities have been identified as potentially modifiable risk factors for many diseases, including mental illness, and may be effective targets for public health policy and intervention. However, the relative contribution of physical activity versus sedentary behaviour to mental health is less clear. This study investigated the cross-sectional association between physical activity, sedentary activity and symptoms of depression and anxiety at age 14-15 in the National Longitudinal Survey of Children and Youth (NLSCY). Methods Respondents aged 14-15years between 1996 and 2009 who reported on symptoms of depression in the NLSCY were included $(n=9702)$. Multinomial logistic regression was used to assess the relationship between physical and sedentary activity and symptoms of depression and anxiety. Joint models including both physical and sedentary activity were also explored. Models were adjusted for sex, ethnicity, immigration status, family income, parental education, recent major stressful life events and chronic health conditions.

Results The odds of having moderate and severe symptoms of depression and anxiety compared with no symptoms was 1.43 (1.11 to 1.84 ) and 1.88 (1.45 to 2.45) times higher, respectively, in physically inactive youth relative to physically active youth. The odds of having moderate and severe symptoms of depression and anxiety compared with no symptoms was 1.38 (1.13 to 1.69) and 1.31 (1.02 to 1.69) times higher, respectively, in sedentary youth relative to non-sedentary youth. In joint models including both physical and sedentary activity, sedentary activity was not consistently associated with symptoms of depression and anxiety.

Conclusions Both physical inactivity and sedentary activity appear to be significantly related to symptoms of depression and anxiety. The importance of distinguishing these two behaviours has relevance for research as well as policies targeting physical activity and mental health in youth.

\section{INTRODUCTION}

It is estimated that more than $20 \%$ of adolescents meet diagnostic criteria for a mental
Strengths and limitations of this study

- The sample was very large $(n=9702)$ and population-based.

- Information was available on numerous potentially confounding factors.

- The temporal association between physical activity, sedentary behaviour and symptoms of depression and anxiety can not be inferred in this study.

- Physical activity and sedentary behaviour were based on self-report.

disorder before the age of $18,{ }^{1}$ and many mental disorders have their origin in adolescence. ${ }^{2}$ Given that the onset of mental illness occurs at a relatively early age compared with other chronic illnesses, it is particularly important to understand the correlates of mental health to identify potentially modifiable risk factors as well as to gain insight into possibilities for intervention. Physical activity such as participation in sports and exercise has benefits for physical health and has been linked in the primary and secondary prevention of a variety of underlying chronic medical conditions $^{3}$ and has also been demonstrated as an effective supplement to treatment for mental health problems. ${ }^{4}$ A sedentary lifestyle has been associated with poor mental health, however the distinction between the two is not often examined. ${ }^{56}$ Intervening early to reduce sedentary activities and increase physical activity may reduce the odds of developing mental illness. ${ }^{7}$

The symptoms of depression and anxiety may include loss of interest in previously enjoyed activities, loss of energy, excessive anxiety, difficulty controlling worry, restlessness and other symptoms which may increase sedentary activity and decrease physical activity frequency. ${ }^{8}$ Recent evidence supports 
an important role of physical activity in promoting both the physical and mental health and well-being in individuals. A study by Wiles $e t$ al suggests that physically active adolescents have lower odds of symptoms of depression, but that no association was detected between the intensity of physical activity and depressive symptoms. ${ }^{9}$ A meta-analysis conducted by Radovic et al concluded that there is some evidence to suggest that physical activity can be used to reduce depressive symptoms in adolescents ${ }^{10}$ which is also supported by a systematic review conducted by Carter et al. ${ }^{11}$ A meta-analysis by Korczak et al demonstrated that physical activity in childhood or adolescence was linked to lower concurrent depressive symptomatology. ${ }^{12}$

Among adolescents, higher levels of screen time was associated with poorer mental health status ${ }^{13}$ and that a dose-response may exist. ${ }^{14}$ However, the evidence is mixed, with some studies showing no link between sedentary activity and depressive symptoms in adolescents. ${ }^{15}$ Individuals with depressive disorders have been demonstrated to spend more time engaged in sedentary activities such as television watching, internet use and video gaming. ${ }^{16-18}$ Participation in sedentary activities, such as video games, has often been described as a coping mechanism for depression. ${ }^{19} 20$ Sedentary activity may also contribute to the development of poor mental health outcomes independent of physical activity. ${ }^{21}$ Sedentary activity may contribute to the development of mental illness through a variety of mechanisms. Sanders et al found that increased internet use has been linked to poorer social ties with friends and mothers, though directionality remained unclear. ${ }^{22}$ Victims of cyber bullying have demonstrably higher levels of both internalising and externalising behavioural issues as a result of the depersonalised nature of online activity. ${ }^{23}$ Some preliminary results have suggested that preference for online communications increases an individual's avoidance of face-toface communications which may lead to social isolation and depression. ${ }^{24}$

It is unclear whether sedentary behaviour on its own increases risk for depression, or whether the association between sedentary behaviour and decreased physical activity drives this association-adolescents may be both very physically active and also engage in sedentary activities. Consequently, the objective of this study was to investigate the association between adolescent depressive symptoms and both sedentary behaviour and physical activity, in a large population-based sample.

\section{METHODS}

\section{Sample}

This study used data from Statistics Canada's National Longitudinal Survey of Children and Youth (NLSCY). The study, which began data collection in 1994, examines the development of children and youth and their physical, mental and social well-being. ${ }^{25}$ The survey was designed using complex survey design to be a representative sample of the children and youth population of
Canada at the time of collection. All respondents aged 14-15 between 1996 and 2009 who responded to questions regarding symptoms of depression and anxiety (see below) were selected and stacked for a single cross-sectional analysis. A total of 11860 respondents were selected, of whom 2158 (18.1\%) respondents did not have any outcome data, resulting in a sample size of 9702 respondents for analysis.

\section{Measures}

Symptoms of depression and anxiety

The primary outcome for this study was symptoms of depression and anxiety, based on seven items taken from the Ontario Child Health Study. ${ }^{26}{ }^{27}$ Items on this scale closely match the Diagnostic and Statistical Manual of Mental Disorders (DSM-III-R) criteria for emotional disorders. ${ }^{28}$ The statements rated are 'I am unhappy or sad', 'I am not as happy as other people my age', 'I am too fearful or nervous', 'I worry a lot', 'I cry a lot', 'I am nervous, high-strung, or tense' and 'I have trouble enjoying myself'. Respondents were asked to rate how well these statements described themselves using the statements 'never or not true', 'sometimes or somewhat true' or 'often or very true'. Cronbach's alpha for this scale for adolescents aged 14-15years ranged from 0.76 to 0.81 , indicating high internal reliability. ${ }^{25}$

Total scores were grouped into four categories representing degrees of severity to account for floor effects (ie, positively skewed distributions): no symptoms (scores below the 50th percentile), mild symptoms (scores between the 51st and 75th percentile), moderate symptoms (scores between the 76th and 90th percentile) and severe symptoms (scores above the 90th percentile). ${ }^{2729} 30$

\section{Leisure time physical activity}

Leisure time physical activity was measured using three questions regarding the frequency of the survey member's participation 'in sports with a coach or instructor (except dance, gymnastics or martial arts) ', '... lessons or instruction in other organized physical activities with a coach or instructor such as dance, gymnastics or martial arts' and 'unorganized sports or physical activities without a coach or instructor? ${ }^{26}$ Respondents were provided with five responses, 'Most days', 'A few times a week', 'About once a week', 'About once a month' and 'Almost never'. Responses were recoded into dichotomous categories, such that 'Physically Active' represents participation in the activity at least once a week or more, and 'Physically Inactive' comprising 'Almost never' and 'About once a month'. ${ }^{31}$ A composite leisure time physical activity score was derived where classification as 'Physically Active' in at least one of the three activities was categorised as 'Physically Active', and others were classified as 'Physically Inactive'.

\section{Sedentary activity}

Sedentary activity was measured with the following question: 'On average, how much time per day does he/ shewatch T.V., videos or DVDs or play video games?' 
Response options of 'none', 'less than $30 \mathrm{~min}$ ', '30 min to less than an hour', ' 1 hour to less than 2 hours', ' 2 hours to less than 3 hours' and ' 3 hours or more'. ${ }^{26} 3233$ This question was validated using a 7-day television viewing diary and had Spearman correlation coefficients of $0.36-0.54$, and test-retest intraclass correlation scores for the reliability of this ranging from 0.76 to $0.81 .^{32} 3435$ Canadian sedentary activity guidelines recommend a maximum 2 hours per day for children aged $5-17 .{ }^{36}$ To be consistent with recommendations, respondents with greater than 2 hours of sedentary activity per day were classified as 'Sedentary'.

\section{Covariates}

Covariates were chosen a priori due to their association with either physical or sedentary activity and symptoms of depression and anxiety. These included age, sex, child's ethnicity (Caucasian or non-Caucasian), whether the respondent was Canadian born, parental education (less than secondary school, completion of secondary school, some postsecondary, university or college degree and other), major stressful life events (see online supplementary table 1), chronic health condition (parent and child reported diagnosed conditions, see online supplementary table 2) and substance use (ever smoked tobacco and ever consumed alcohol). A measure of income relative to neighbourhood average income was included using the Low Income Cut-Off (LICO) ratio. This measure is the ratio of a family's income divided by the LICO for that family's neighbourhood. Additionally, a variable indicating from which cycle of the NLSCY the participant was from was added to account for the cohort effect.

\section{Analysis}

Multinomial logistic regression was used to examine the relationship between physical and sedentary activity and symptoms of depression and anxiety. Odds ratios (ORs) were obtained for unadjusted models, as well as a model controlling for covariates.

All frequencies, means and models were weighted using bootstrapping survey weights to account for complex survey design. In order to retain the greatest number of respondents during the analysis, for each categorical variable an additional category of 'missing' was created. Individuals with incomplete or no outcome data, or who were missing observations for continuous variables (age, LICO ratio) were dropped. A sensitivity analysis using only respondents with complete data was conducted. Sex-stratified models were also run. A model including an interaction term between physical and sedentary activity categories was also run.

All statistical analyses were conducted using SAS V.9.4 (SAS Institute).

\section{Patient and public involvement}

This study is based on analysis of previously collected data. Patients or members of the public were not involved in this study.

\section{RESULTS}

Respondents tended to be physically active $(76.4 \%)$ but also frequently engaged in sedentary behaviours (45.4\%) (table 1). They were primarily Caucasian (87.0\%). Respondents' parents tended to have high levels of education $(46.3 \%$ were university or college educated) and were primarily Canadian born $(74.5 \%)$. Respondents who reported higher symptoms of depression and anxiety were more likely to be female, have a chronic health condition, have experienced recent stressful life events, have tried tobacco and have a low family income. Respondents who reported higher symptoms of depression and anxiety were less likely to be physically active but did not differ in their level of sedentary activity (table 1 ).

Physical inactivity was associated with increased odds of moderate and severe symptoms of depression and anxiety in both unadjusted and adjusted models (table 2). Sedentary behaviour was associated with increased odds of moderate and severe symptoms of depression and anxiety, but not mild symptoms (table 2).

In the joint model that included both leisure time physical activity and sedentary activity (table 3 ), being physically inactive was statistically significantly associated with having higher odds of being in the moderate symptoms of depression and anxiety category (OR 1.40, 95\% CI: 1.09 to 1.79 ), and the severe symptoms of depression and anxiety category (OR 1.84, 95\% CI: 1.42 to 2.41). Those who were sedentary had 1.36 times the odds (95\% CI: 1.11 to 1.67) of being in the moderate symptoms of depression and anxiety category.

Sex-stratified models showed no significant differences in the associations between sexes. The sensitivity analysis using cases with complete data only provided results consistent with those presented here. The model including an interaction between physical and sedentary activity showed no significant interactions.

\section{DISCUSSION AND CONCLUSIONS}

In a population-based study of more than 9700 adolescents, lower leisure time physical activity was associated with higher symptoms of depression and anxiety whereas sedentary activity appeared to have less consistent patterns with symptoms of depression and anxiety.

\section{Leisure time physical activity}

Results from this study suggest that individuals who reported engaging in leisure time physical activity less than 1 day per week were at higher risk for being in higher depression and anxiety symptoms categories compared with those reporting at least 1 day of physical activity per week, suggesting that physical activity may be protective against depression. This finding is largely consistent with previous research demonstrating associations between physical inactivity and depression. Sund et al demonstrated that low levels of vigorous physical activity were associated with depressive symptoms levels cross-sectionally, and that low levels of vigorous physical activity were 
Table 1 Weighted proportion of respondents by symptoms of depression and anxiety category and outcome/covariates $†$

Symptoms of depression and anxiety category

\begin{tabular}{|c|c|c|c|c|c|}
\hline & Total & None & Mild & Moderate & Severe \\
\hline Total (unweighted $n=9702)$ ) & $100 \%$ & $56.5 \%$ & $21.1 \%$ & $13.3 \%$ & $9.1 \%$ \\
\hline \multicolumn{6}{|c|}{$\begin{array}{l}\text { Physical activity } \\
\text { category }^{\star \star \star}\end{array}$} \\
\hline Active & $76.4 \%$ & $80.3 \%$ & $74.7 \%$ & $70.8 \%$ & $64.9 \%$ \\
\hline Not active & $22.7 \%$ & $18.9 \%$ & $24.3 \%$ & $28.3 \%$ & $34.4 \%$ \\
\hline Missing & $0.9 \%$ & $0.9 \%$ & $1.0 \%$ & $0.9 \%$ & $0.7 \%$ \\
\hline
\end{tabular}

Sedentary activity

category

\begin{tabular}{|c|c|c|c|c|c|c|}
\hline Sedentary & $45.4 \%$ & $43.9 \%$ & $45.7 \%$ & $49.5 \%$ & $47.4 \%$ & \\
\hline Not sedentary & $53.3 \%$ & $54.7 \%$ & $53.1 \%$ & $49.1 \%$ & $51.2 \%$ & \\
\hline Missing & $1.3 \%$ & $1.4 \%$ & $1.2 \%$ & $1.4 \%$ & $1.4 \%$ & \\
\hline $\operatorname{Sex}{ }^{\star \star \star}$ & & & & & & $<0.001$ \\
\hline Male & $49.9 \%$ & $59.3 \%$ & $43.4 \%$ & $35.7 \%$ & $27.6 \%$ & \\
\hline Female & $50.1 \%$ & $40.7 \%$ & $56.6 \%$ & $64.3 \%$ & $72.4 \%$ & \\
\hline Ethnicity & & & & & & 0.832 \\
\hline Caucasian & $87.0 \%$ & $88.0 \%$ & $86.0 \%$ & $85.4 \%$ & $86.1 \%$ & \\
\hline Non-Caucasian & $7.8 \%$ & $7.3 \%$ & $8.6 \%$ & $8.7 \%$ & $7.9 \%$ & \\
\hline Missing & $5.2 \%$ & $4.8 \%$ & $5.4 \%$ & $5.9 \%$ & $5.9 \%$ & \\
\hline $\begin{array}{l}\text { Education of person most } \\
\text { knowledgeable (PMK) }\end{array}$ & & & & & & 0.365 \\
\hline Less than secondary & $12.2 \%$ & $11.4 \%$ & $12.5 \%$ & $15.6 \%$ & $11.4 \%$ & \\
\hline Secondary school & $23.9 \%$ & $24.0 \%$ & $24.8 \%$ & $23.2 \%$ & $21.9 \%$ & \\
\hline Some postsecondary & $16.8 \%$ & $15.8 \%$ & $17.6 \%$ & $17.0 \%$ & $20.9 \%$ & \\
\hline $\begin{array}{l}\text { University/college } \\
\text { degree }\end{array}$ & $46.3 \%$ & $47.9 \%$ & $44.1 \%$ & $43.5 \%$ & $45.5 \%$ & \\
\hline Other & $<0.1 \%$ & $0.4 \%$ & $0.6 \%$ & $0.4 \%$ & $0.2 \%$ & \\
\hline Missing & $<0.1 \%$ & $0.4 \%$ & $0.4 \%$ & $0.2 \%$ & $0.1 \%$ & \\
\hline PMK Canadian born & & & & & & 0.361 \\
\hline Yes & $74.5 \%$ & $75.9 \%$ & $74.5 \%$ & $70.0 \%$ & $72.6 \%$ & \\
\hline No & $14.9 \%$ & $13.8 \%$ & $15.5 \%$ & $18.3 \%$ & $15.5 \%$ & \\
\hline Missing & $10.6 \%$ & $10.3 \%$ & $10.0 \%$ & $11.8 \%$ & $11.9 \%$ & \\
\hline $\begin{array}{l}\text { Presence of chronic } \\
\text { condition }^{*}\end{array}$ & & & & & & 0.024 \\
\hline Yes & $31.1 \%$ & $30.5 \%$ & $30.3 \%$ & $28.9 \%$ & $39.2 \%$ & \\
\hline No & $67.3 \%$ & $68.0 \%$ & $68.0 \%$ & $69.4 \%$ & $57.9 \%$ & \\
\hline Missing & $1.7 \%$ & $1.5 \%$ & $1.7 \%$ & $1.7 \%$ & $2.9 \%$ & \\
\hline Stressful life event ${ }^{\star \star \star}$ & & & & & & $<0.001$ \\
\hline Yes & $33.3 \%$ & $29.6 \%$ & $35.4 \%$ & $38.9 \%$ & $42.9 \%$ & \\
\hline No & $65.6 \%$ & $69.4 \%$ & $63.6 \%$ & $59.7 \%$ & $55.6 \%$ & \\
\hline Missing & $1.1 \%$ & $1.0 \%$ & $1.0 \%$ & $1.4 \%$ & $1.5 \%$ & \\
\hline $\begin{array}{l}\text { Child ever smoked } \\
\text { tobacco*** }\end{array}$ & & & & & & $<0.001$ \\
\hline Yes & $39.1 \%$ & $34.8 \%$ & $40.3 \%$ & $48.1 \%$ & $49.5 \%$ & \\
\hline No & $59.6 \%$ & $63.9 \%$ & $58.1 \%$ & $50.7 \%$ & $49.2 \%$ & \\
\hline Missing & $1.3 \%$ & $1.2 \%$ & $1.6 \%$ & $1.2 \%$ & $1.3 \%$ & \\
\hline
\end{tabular}

Continued 
Table 1 Continued

\begin{tabular}{|c|c|c|c|c|c|c|}
\hline & \multicolumn{5}{|c|}{ Symptoms of depression and anxiety category } & \multirow[b]{2}{*}{$\chi^{2}$ p values } \\
\hline & Total & None & Mild & Moderate & Severe & \\
\hline $\begin{array}{l}\text { Child ever consumed } \\
\text { alcohol }\end{array}$ & & & & & & 0.094 \\
\hline Yes & $76.1 \%$ & $75.2 \%$ & $74.3 \%$ & $80.1 \%$ & $80.0 \%$ & \\
\hline No & $22.3 \%$ & $23.3 \%$ & $24.1 \%$ & $18.4 \%$ & $18.3 \%$ & \\
\hline \multicolumn{7}{|c|}{ Weighted means and SEs of respondents by symptoms of depression and anxiety category and covariates } \\
\hline & \multicolumn{4}{|c|}{$\begin{array}{l}\text { Symptoms of depression and anxiety category } \\
\text { mean (SE) }\end{array}$} & \multirow{2}{*}{\multicolumn{2}{|c|}{ F-test $p$ values }} \\
\hline & None & Mild & Moderate & Severe & & \\
\hline Age & $14.5(0.023)$ & $14.5(0.024)$ & $14.6(0.031)$ & $14.5(0.036)$ & 0.620 & \\
\hline
\end{tabular}

$\chi^{2}$ and F-test: ${ }^{\star} p<0.05^{* *} p<0.01{ }^{\star * *} p<0.001$.

†Some percentages may not add up to exactly $100 \%$ due to rounding.

$\ddagger$ The ratio between a family's income divided by the low-income cut-off (LICO) for that family's neighbourhood. A value greater than 1 indicates a family has a family income greater than the LICO for that neighbourhood, whereas a value below 1 would indicate a level beneath the LICO.

associated with high depressive symptoms levels 1 year later in boys, but not in girls. ${ }^{5}$ This study did find a similar association for boys and girls in terms of lower physical activity levels and increased odds of depressive symptoms.

Physical activity has been studied as a psychosocial buffer against symptoms of depression and anxiety because it can provide social support, increase self-esteem, and engender a feeling of achievement and validation. ${ }^{37} 38$ This finding is important because physical activity is a modifiable risk factor and is amenable to intervention. ${ }^{39}{ }^{40}$ Interventions aimed at increasing physical activity among youth may have beneficial effects on risk of depressive symptoms in children and youth, ${ }^{41}$ as well as other positive physical health benefits. ${ }^{43}$

\section{Sedentary activity}

Our results show that sedentary activity was associated with increased odds of moderate and severe symptoms of depression and anxiety. This pattern has been seen in the existing literature. For example, Sund et al demonstrated that higher levels of sedentary activity were associated with higher depressive symptoms over time. ${ }^{5}$ Additionally, a study of Canadian youth demonstrated an association between increased screen-time and severe symptoms of depression and anxiety. ${ }^{18}$ In contrast, Hume et al did not find any cross-sectional or longitudinal associations between sedentary time and depressive symptoms among either boys or girls with a mean age of 14 years. ${ }^{15}$ The

Table 2 Results of bootstrapped multinomial logistic regression modelling

\section{Adjusted physical and sedentary activity models}

\section{Symptoms of depression and anxiety category Unadjusted OR ( $95 \% \mathrm{Cl})$ (weighted)}

\begin{tabular}{lll}
\hline Mild vs none Moderate vs none $\quad$ Severe vs none &
\end{tabular}

Model 1: adjusted physical activity ${ }^{*}(\mathrm{n}$ missing $=40$ ) Active (reference)

\begin{tabular}{|c|c|c|c|}
\hline Not active & 1.23 (0.99 to 1.52$)$ & 1.43 (1.11 to 1.84$) \dagger$ & $1.88(1.45$ to 2.45$) \dagger$ \\
\hline Missing & 1.11 (0.53 to 2.31$)$ & 1.25 (0.52 to 3.00$)$ & 1.08 (0.29 to 4.10$)$ \\
\hline \multicolumn{4}{|c|}{ 1odel 2: adjusted sedentary activity ${ }^{*}(\mathrm{n}$ missing $=40$ ) } \\
\hline Not sedentary (reference) & - & - & - \\
\hline Sedentary & 1.13 (0.94 to 1.36$)$ & 1.38 (1.13 to 1.69$) \dagger$ & 1.31 (1.02 to 1.69$) \dagger$ \\
\hline Missing & 0.87 (0.41 to 1.81$)$ & 1.30 (0.68 to 2.51$)$ & 1.50 (0.58 to 3.86$)$ \\
\hline
\end{tabular}

*Adjusted for age, sex, child's ethnicity, whether the respondent was Canadian born, parental education, major stressful life, chronic health condition, substance use (tobacco and alcohol), cycle number and low-income cut-off ratio.

†Statistically significant at $\alpha=0.05$. 
Table 3 Results of bootstrapped multinomial logistic regression modelling

\section{Joint adjusted sedentary and physical activity}

Symptoms of depression and anxiety category

Unadjusted OR $(95 \% \mathrm{Cl})$ (weighted)

\begin{tabular}{|c|c|c|c|}
\hline \multirow[b]{2}{*}{ Adjusted model * (n missing $=40$ ) } & & & \\
\hline & Mild vs none & Moderate vs none & Severe vs none \\
\hline \multicolumn{4}{|l|}{ Sedentary activity category } \\
\hline Not sedentary (reference) & - & - & - \\
\hline Missing & 0.81 (0.35 to 1.86$)$ & 1.24 (0.57 to 2.69$)$ & $1.58(0.54$ to 4.69$)$ \\
\hline \multicolumn{4}{|l|}{ Physical activity category } \\
\hline Not active & 1.21 (0.98 to 1.51$)$ & $1.40(1.09$ to 1.79$) \dagger$ & $1.85(1.42$ to 2.41$) \dagger$ \\
\hline Missing & 1.25 (0.35 to 1.86$)$ & 1.24 (0.45 to 3.40$)$ & $0.93(0.21$ to 4.17$)$ \\
\hline
\end{tabular}

${ }^{*}$ Adjusted for age, sex, child's ethnicity, whether the respondent was Canadian born, parental education, major stressful life, chronic health condition, substance use (tobacco and alcohol), cycle number and low-income cut-off ratio.

†Statistically significant at $\alpha=0.05$.

Hume study, however, had a small sample size $(\mathrm{n}=155)$ and skewed heavily female ( $60 \%$ of sample) compared with the Sund study which had a much larger sample $(\mathrm{n}=2$ 644) with a more even distribution of males and females. Furthermore, a systematic review of sedentary activity and depression has shown that sedentary activity may be a risk factor for depression, independent of physical activity, though the studies reviewed demonstrated methodological weaknesses such as small sample sizes and poor measures of sedentary activity. ${ }^{21}$ This may explain the contradictory results.

\section{Joint physical and sedentary activity}

When both sedentary and leisure-time physical activity were included in the same model, sedentary activity was associated with moderate but not with severe symptoms of depression and anxiety. While the OR in the sedentary activity only model and the joint model were close (1.31 vs 1.26$)$, it is possible that the slight attenuation of the effect as a result of including physical activity in the model led to the loss of statistical significance for those with severe symptoms of depression and anxiety.

\section{Strengths and limitations}

The large, nationally representative sample included in this study supports smaller studies which have shown similar associations between participation in physical activity and reduced levels of symptoms of depression and anxiety. The data in the NLSCY, although somewhat dated, show associations that we would not expect to change given more recent data. Modern trends indicate a rise in screen use among adolescents. Recent studies have suggested that moderate use of digital screens may not be harmful and may confer some benefits. ${ }^{44}$ As this is the only population-based study examining physical and sedentary activity and its relationship with symptoms of depression and anxiety in Canadian youth, this study warrants replication with other sources of data. The large sample size allows sufficient power to detect smaller effects and to include a more nuanced approach to covariate selection to properly adjust for a number of mitigating factors as was done in this study.

The use of self-reported physical and sedentary activity has the potential to introduce bias. Studies have demonstrated that individuals tend to over-report their physical activity levels compared with objectively ascertained methods such as accelerometry. ${ }^{45}$ This may misclassify physical activity levels, such that the number of participants who are truly physically active are lower than those reported in this study. This misclassification may bias results.

More precise and objective measures of physical activity may yield different results due to lower reporting bias and recall bias. Research by Parfitt et al demonstrated that higher levels of vigorous physical activity were predictive of higher self-worth, but not statistically significantly associated with depressive symptoms. ${ }^{46}$ Parfitt's study used accelerometry to measure physical activity level, a more objective and precise measurement of physical activity. In addition to more objective measures of physical activity, having longitudinal data, as opposed to point measurements, would lead to more robust analyses that would be helpful in understanding the directionality of associations.

Having better survey measures to capture other types of physical and sedentary activity, such as active community, incidental physical activity and non-screen-based sedentary activity could provide more robust and nuanced results.

Similarly, the definition of sedentary activity used in the present study may have been too restrictive. The Canadian Sedentary Activity Guidelines recommend no more than 2 hours per day of sedentary activity. However, it is possible that associations with depression are stronger at higher levels of sedentary activity. 


\section{CONCLUSIONS}

The present study suggests that physical inactivity is associated with increased risk of symptoms of depression and anxiety among youth, while associations between sedentary behaviour and depressive symptoms are less clear. Interventions aimed at making youth more physically active may be effective in reducing risk of mental illness.

Contributors This study was conceived and designed by $M-A B, I C$ and DEK. M-AB did the data analysis. M-AB, IC, DEK and MK interpreted the results. M-AB wrote the first draft of the manuscript. IC, DEK and MK critically reviewed the manuscript and approved it for submission.

Funding This research was undertaken, in part, thanks to funding from the Canada Research Chairs program.

Competing interests None declared.

Patient consent Not required.

Ethics approval This study received ethical approval from the Ottawa Hospital Research Ethics Boards.

Provenance and peer review Not commissioned; externally peer reviewed.

Data sharing statement Data for this study are available for research use through Statistics Canada's Research Data Centre programme.

Open access This is an open access article distributed in accordance with the Creative Commons Attribution Non Commercial (CC BY-NC 4.0) license, which permits others to distribute, remix, adapt, build upon this work non-commercially, and license their derivative works on different terms, provided the original work is properly cited, appropriate credit is given, any changes made indicated, and the use is non-commercial. See: http://creativecommons.org/licenses/by-nc/4.0/.

\section{REFERENCES}

1. Merikangas KR, He JP, Burstein M, et al. Lifetime prevalence of mental disorders in U.S. adolescents: results from the National Comorbidity Survey Replication-Adolescent Supplement (NCS-A). J Am Acad Child Adolesc Psychiatry 2010;49:980-9.

2. Kessler RC, Berglund P, Demler O, et al. Lifetime prevalence and age-of-onset distributions of DSM-IV disorders in the National Comorbidity Survey Replication. Arch Gen Psychiatry 2005;62:593-602.

3. Kyu HH, Bachman VF, Alexander LT, et al. Physical activity and risk of breast cancer, colon cancer, diabetes, ischemic heart disease, and ischemic stroke events: systematic review and dose-response meta-analysis for the Global Burden of Disease Study 2013. BMJ 2016;354:i3857.

4. Cooney GM, Dwan K, Greig CA, et al. Exercise for depression: some benefits but better trials are needed. Cochrane Database Syst Rev 2013;9.

5. Sund AM, Larsson B, Wichstrøm L. Role of physical and sedentary activities in the development of depressive symptoms in early adolescence. Soc Psychiatry Psychiatr Epidemiol 2011;46:431-41.

6. Anton SD, Newton RL, Sothern M, et al. Association of depression with body mass index, sedentary behavior, and maladaptive eating attitudes and behaviors in 11 to 13-year old children. Eat Weight Disord 2006;11:e102-e108.

7. Harvey SB, Hotopf M, Overland S, et al. Physical activity and common mental disorders. Br J Psychiatry 2010;197:357-64.

8. American Psychiatric Association. Diagnostic and statistical manual of mental disorders: American Psychiatric Association, 2000.

9. Wiles NJ, Haase AM, Lawlor DA, et al. Physical activity and depression in adolescents: cross-sectional findings from the ALSPAC cohort. Soc Psychiatry Psychiatr Epidemiol 2012;47:1023-33.

10. Radovic S, Gordon MS, Melvin GA. Should we recommend exercise to adolescents with depressive symptoms? A meta-analysis. J Paediatr Child Health 2017;53:214-20.

11. Carter T, Morres ID, Meade O, et al. The effect of exercise on depressive symptoms in adolescents: a systematic review and metaanalysis. J Am Acad Child Adolesc Psychiatry 2016;55:580-90.

12. Korczak DJ, Madigan S, Colasanto M, et al. and Depression: a metaanalysis. Pediatrics 2017;139:e20162266.

13. Hoare $\mathrm{E}$, Milton $\mathrm{K}$, Foster $\mathrm{C}$, et al. The associations between sedentary behaviour and mental health among adolescents: a systematic review. Int J Behav Nutr Phys Act 2016;13:108.
14. Liu M, Wu L, Yao S. Dose-response association of screen timebased sedentary behaviour in children and adolescents and depression: a meta-analysis of observational studies. Br J Sports Med 2016;50:1252-8

15. Hume C, Timperio A, Veitch J, et al. Physical activity, sedentary behavior, and depressive symptoms among adolescents. J Phys Act Health 2011;8:152-6.

16. de Wit L, van Straten A, Lamers F, et al. Are sedentary television watching and computer use behaviors associated with anxiety and depressive disorders? Psychiatry Res 2011;186:239-43.

17. Ko CH, Yen JY, Yen CF, et al. The association between Internet addiction and psychiatric disorder: a review of the literature. Eur Psychiatry 2012;27:1-8.

18. Maras D, Flament MF, Murray M, et al. Screen time is associated with depression and anxiety in Canadian youth. Prev Med 2015;73:133-8

19. Li D, Liau A, Khoo A. Examining the influence of actual-ideal self-discrepancies, depression, and escapism, on pathological gaming among massively multiplayer online adolescent gamers. Cyberpsychol Behav Soc Netw 2011;14:535-9.

20. Dupuis EC, Ramsey MA. The relation of social support to depression in massively multiplayer online role-playing games. J App/ Soc Psychol 2011;41:2479-91.

21. Teychenne M, Ball K, Salmon J. Sedentary behavior and depression among adults: a review. Int J Behav Med 2010;17:246-54.

22. Sanders CE, Field TM, Diego M, et al. The relationship of Internet use to depression and social isolation among adolescents. Adolescence 2000;35:793-7.

23. Hay C, Meldrum R, Mann K. Traditional bullying, cyber bullying, and deviance: a general strain theory approach. J Contemp Crim Justice 2010;26:130-47.

24. Lee BW, Stapinski LA. Seeking safety on the internet: relationship between social anxiety and problematic internet use. J Anxiety Disord 2012;26:197-205.

25. Human Resources and Skills Development Canada. National Longitudinal Survey of Children and Youth (NLSCY). Ottawa: Statistics Canada, 2010.

26. Human Resources and Skills Development Canada. National Longitudinal Survey of Children and Youth - User Guide (Cycle 8). Ottawa: Statistics Canada, 2010.

27. Naicker K, Wickham M, Colman I. Timing of first exposure to maternal depression and adolescent emotional disorder in a national Canadian cohort. PLoS One 2012;7:e33422.

28. Boyle $\mathrm{MH}$, Offord $\mathrm{DR}$, Racine $\mathrm{Y}$, et al. evaluation of the original ontario child health study scales. The Canadian Journal of Psychiatry 1993;38:397-405.

29. Colman I, Ataullahjan A, Naicker K, et al. Birth weight, stress, and symptoms of depression in adolescence: evidence of fetal programming in a national Canadian cohort. The $J$ Psychiatry - Rev Can Psychiatr 2012;57:422-8.

30. Weeks M, Wild TC, Ploubidis GB, et al. Childhood cognitive ability and its relationship with anxiety and depression in adolescence. $J$ Affect Disord 2014;152:139-45.

31. Arim RG, Findlay LC, Kohen DE. Participation in physical activity for children with neurodevelopmental disorders. Int J Pediatr 2012;2012:1-9.

32. Alamian A, Paradis G. Individual and social determinants of multiple chronic disease behavioral risk factors among youth. BMC Public Health 2012;12:224.

33. Tremblay MS, Willms JD. Is the Canadian childhood obesity epidemic related to physical inactivity? Int $J$ Obes Relat Metab Disord 2003;27:1100-5.

34. Wold B, Aaro LE, Smith C. Health behaviour in school-aged children: a WHO cross-national study, research protocol for the 19931994 survey. 1993.

35. Vereecken CA, Todd J, Roberts C, et al. Television viewing behaviour and associations with food habits in different countries. Public Health Nutr 2006;9:244-50.

36. Canadian Society for Exercise Physiology. Canadian sedentary behaviour guidelines 2012. Ottawa: Canadian Society for Exercise Physiology, 2012.

37. Sigfusdottir ID, Asgeirsdottir BB, Sigurdsson JF, et al. Physical activity buffers the effects of family conflict on depressed mood: a study on adolescent girls and boys. J Adolesc 2011;34:895-902.

38. Babiss LA, Gangwisch JE. Sports participation as a protective factor against depression and suicidal ideation in adolescents as mediated by self-esteem and social support. J Dev Behav Pediatr 2009;30:376-84

39. Hobkirk JP, King RF, Gately P, et al. Longitudinal factor analysis reveals a distinct clustering of cardiometabolic improvements during 
intensive, short-term dietary and exercise intervention in obese children and adolescents. Metab Syndr Relat Disord 2012;10:20-5.

40. Maggio AB, Aggoun Y, Martin XE, et al. Long-term follow-up of cardiovascular risk factors after exercise training in obese children. Int J Pediatr Obes 2011;6:e603-e610.

41. Janssen I, Leblanc AG. Systematic review of the health benefits of physical activity and fitness in school-aged children and youth. Int $J$ Behav Nutr Phys Act 2010;7:40.

42. Penedo FJ, Dahn JR. Exercise and well-being: a review of mental and physical health benefits associated with physical activity. Curr Opin Psychiatry 2005;18:189-93.
43. Adami PE, Negro A, Lala N, et al. The role of physical activity in the prevention and treatment of chronic diseases. Clin Ter 2010;161:537-41.

44. Przybylski AK, Weinstein N. A large-scale test of the goldilocks hypothesis. Psychol Sci 2017;28:204-15.

45. Adamo KB, Prince SA, Tricco AC, et al. A comparison of indirect versus direct measures for assessing physical activity in the pediatric population: a systematic review. Int J Pediatr Obes 2009;4:2-27.

46. Parfitt G, Eston RG. The relationship between children's habitual activity level and psychological well-being. Acta Paediatr 2005;94:1791-7. 